\title{
Creating a biodiversity inventory in protected areas to increase knowledge of their natural heritage and to improve land management
}

\author{
Marta De Biaggi, Marie-France Leccia, Alexander Kroupa \& Juan Carlos Monje
}

Keywords: protected area, biodiversity, taxonomy, inventory

\section{Abstract}

The Mercantour National Park and the Alpi Marittime Natural Park are working together to create the first complete inventory of the biodiversity on their territory. The project, called All Taxa Biodiversity Inventory+Monitoring, represents a unique opportunity for protected areas to gather an impressive amount of information on their natural heritage from the work of taxonomists and other scientists from all over Europe. The inventory is an extremely useful source of knowledge for defining conservation strategies compatible with local land use and for assessing the changes in species richness and ecosystem functions through monitoring activities.

\section{Introduction}

Protecting and conserving natural resources has become a major issue for national and international environmental policies and many, if not all, environmental management institutions, together with research institutes, have recently been called upon to contribute. Defining appropriate conservation strategies for the natural heritage needs to be based on a good knowledge of its composition and ecological requirements. Indeed, taxonomy is the key tool for improving knowledge on biodiversity. The European Distributed Institute of Taxonomy (EDIT) is taking part in this great challenge, bringing together the leading taxonomic institutions in Europe (with the collaboration of NorthAmerican and Russian partners), supporting research activities, managing biodiversity data, facilitating the dissemination of taxonomic knowledge to a wider audience and training a young generation of taxonomists. In 2006, EDIT put into practice its strategy with the definition of the first European All Taxa Biodiversity Inventory + Monitoring $(\mathrm{ATBI}+\mathrm{M})$ project along the lines of North American precursors. An ATBI+M has the aim of enhancing knowledge on the biodiversity found in a given space over a short period of time through massive and intensive efforts on the part of taxonomy experts. The long-term orientation and the wide-ranging connotations distinguish this approach from other more traditional ones.

Indeed, an ATBI+M is mainly focused on taxonomic research with the aim of providing a substantial increase in knowledge, especially of the least studied taxa present in the target area, through the use of pioneering techniques for living organisms (barcoding, computer data processing). The involvement of all major European research institutes in activities that take place within a restricted area fosters the creation of new dynamics for taxonomy, provides an opportunity for exchange between experts, administrators and government agencies and improves the dissemination of the knowledge gained among the wider public.

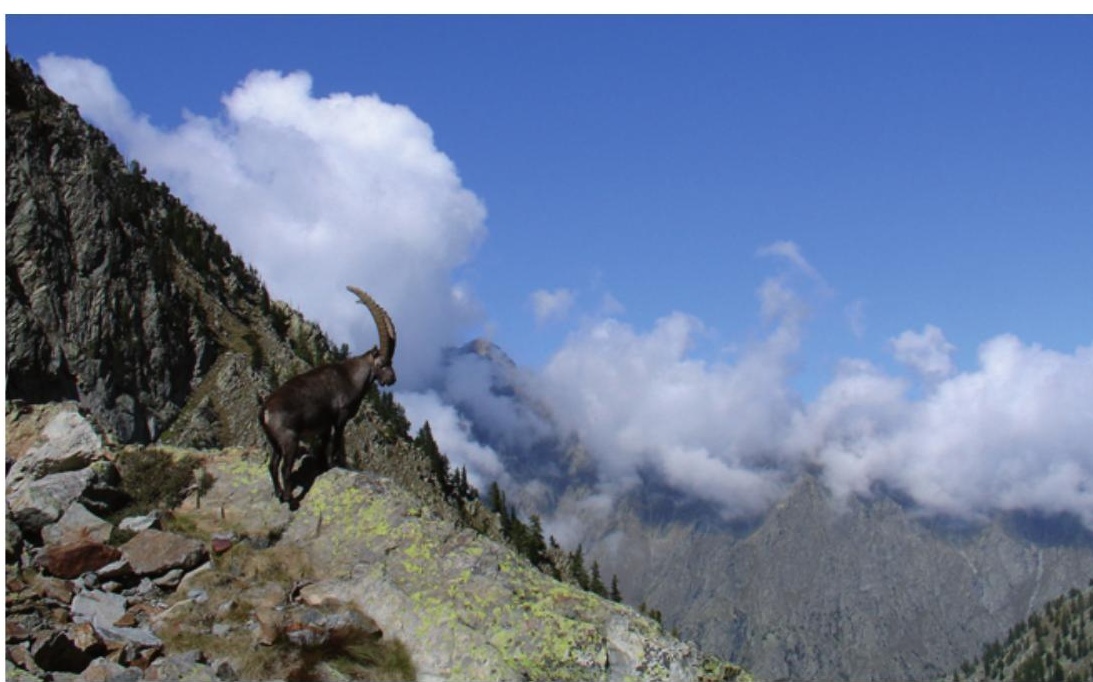

Alpi Marittime Natural Park. (C) Giorgio Bernardi / Arch. PNAM

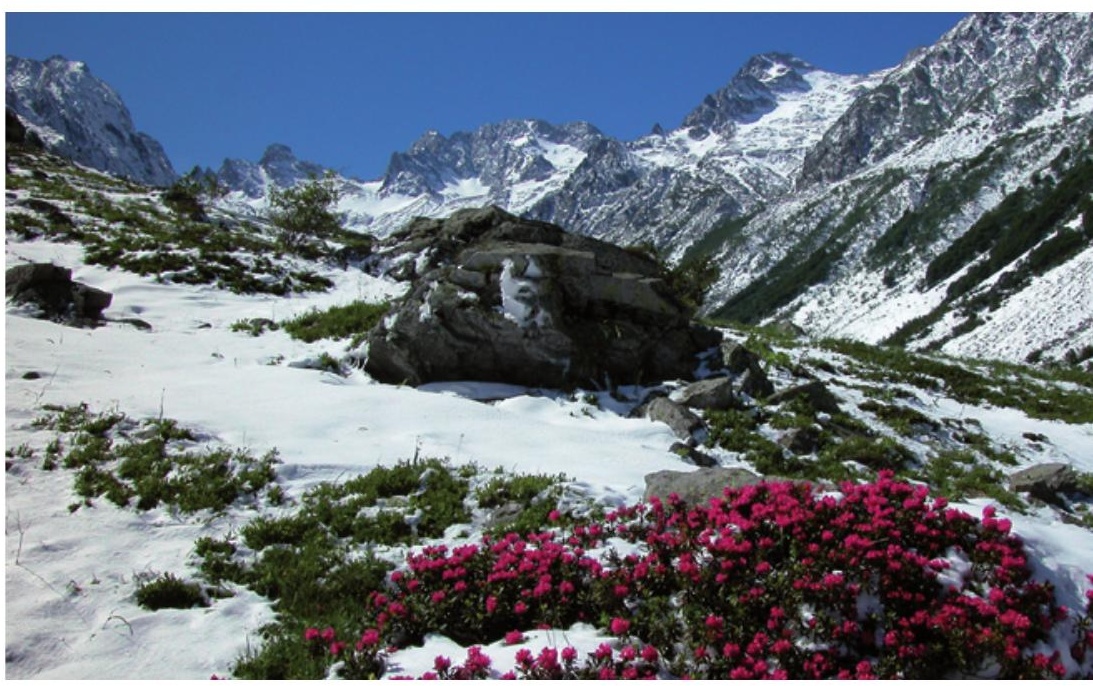

Alpi Marittime Natural Park. (C) Augusto Rivelli

\section{Protected areas}

Protected areas have an important role in this context. Their institutional duties include the conservation of all natural resources present on their territory. Natural parks are an important link between the area and the 


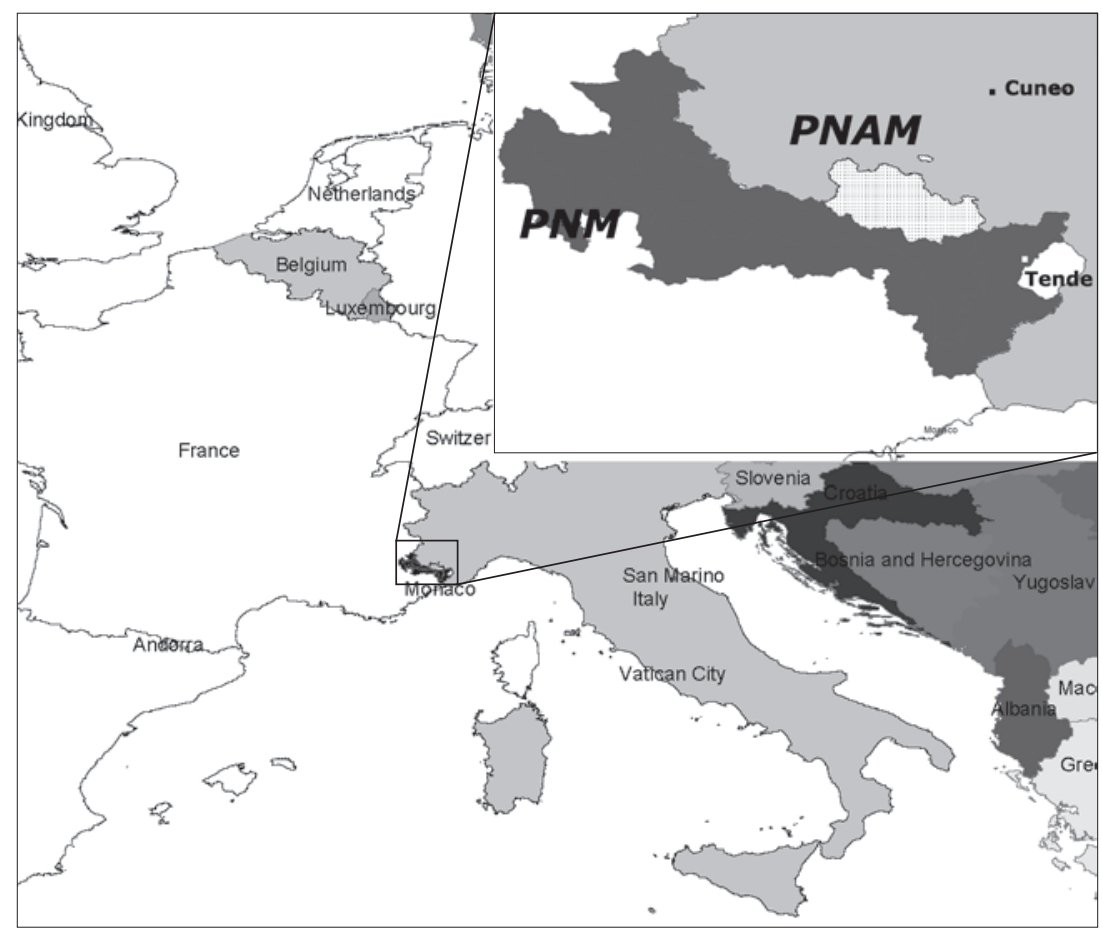

Figure 1 - Position of the Mercantour/Marittime territory, with a close-up of Mercantour National Park. (PNM) and Alpi Marittime Natural Park. (PNAM)

local population who needs to be part of the planned conservation strategy.

Alpi Marittime Natural Park and Mercantour National Park

The Alpi Marittime Natural Park (PNAM) and the Mercantour National Park (PNM) are located in the south-western part of the Alps and cover $2330 \mathrm{~km}^{2}$ in total (including peripheral areas).

The Mercantour/Marittime territory (Figure 1) lies at the crossroads of climatic and biogeographical factors (continental, alpine and Mediterranean climate influences) and benefits from a great diversity of altitudes, exposures as well as geological and pedological substrata. This set of characteristics makes the area a hotspot of biodiversity with an indispensible value in terms of biological species richness. In addition, changes in the equilibrium of all ecosystems due to human activities (including climate change) make the mountainous zones particularly vulnerable.

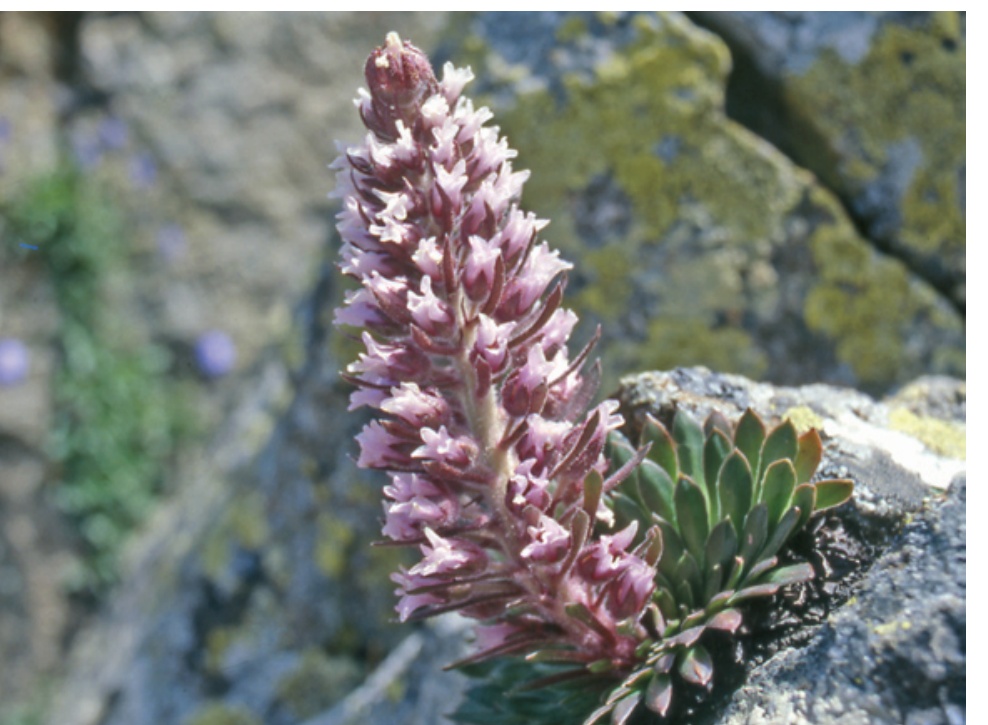

All Taxa Biodiversity Inventory + Monitoring Project

The two parks have a long history of cooperation. For over 15 years they have shared the same conservation concerns and strategies. Thanks to the collaboration between the Mercantour National Park and the National Museum of Natural History in Paris (MNHN) as EDIT partner, the Mercantour/Alpi Marittime territory was taken into consideration as an All Taxa Biodiversity Inventory + Monitoring $(\mathrm{ATBI}+\mathrm{M})$ site and approved almost immediately because of its conservation interest and the ready infrastructure.

Since 2007, almost 200 researchers from all over Europe, mostly affiliated to scientific institutions, have visited the area, collected and identified specimens and established close cooperation with other specialists. Each year, the ATBI+M fieldwork activities take place mainly between mid-May and the end of September, depending on snow cover.

From 2007 to 2008, fieldwork activities were focused on 17 key sites, identified by EDIT and the two parks. From 2009, we encouraged the scientists to expand their study area so as to gain information on the biodiversity in the whole territory of both protected areas.

Taxonomists from almost 60 scientific institutions, together with freelance researchers and students, joined their efforts to inventory all the taxa they are specialized in. Since 2009, workgroups have been organized for some of the research activities to improve the efficiency of the inventorying activities (less redundancy in collected species, shared experience, sampled biological material distributed to a pool of experts, etc.). These groups focus on specific taxonomic groups, habitats and sampling methods.

Our intention is to define sampling and identification protocols and to introduce innovative techniques for establishing a research strategy that may be used in future monitoring and similar projects. Workgroups are indeed important because it is their duty to produce such protocols with the help of a scientific advisory board that reunites several Italian and French taxonomists and other conservation experts.

As the inventory includes all living species, we are currently trying to involve experts on less studied groups or on higher taxa on which information is still scarce. Some workgroups are involved in ecological studies on specific areas. The inventory is an important opportunity for scientists to carry out wider research on habitat conditions and on the impact of human activities on the environment. In both parks there are 


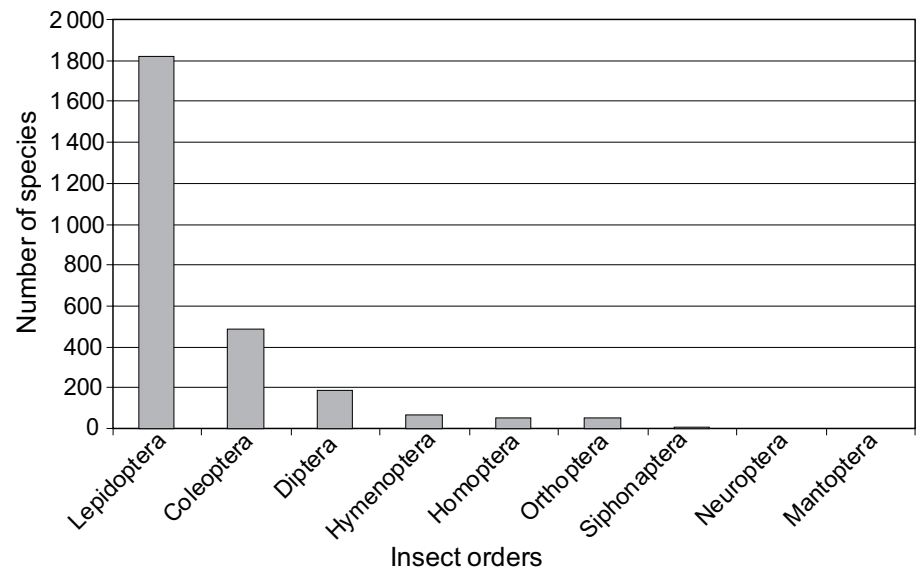

Figure 2 - Number of species identified within different insect orders

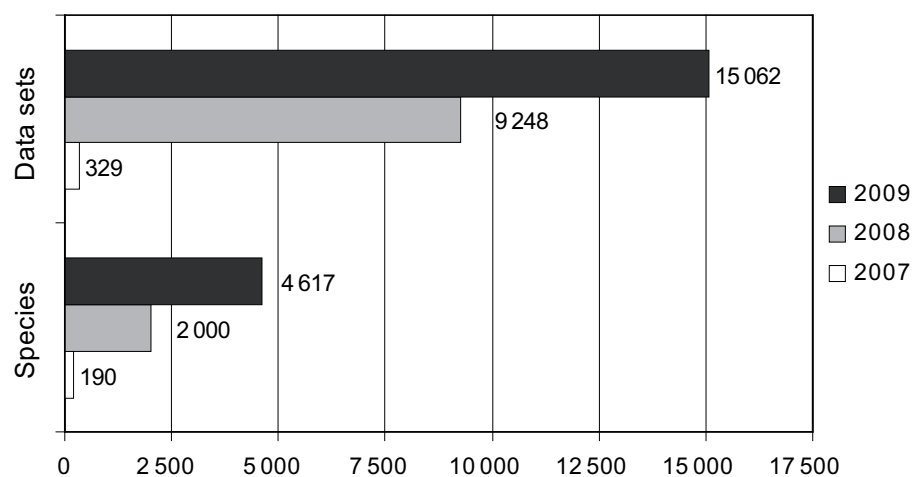

Figure 3 - Increase in the number of data sets and species recorded by December 2009

areas in which some forms of land use are allowed, e.g. as grazing, tree felling and farming. Their impact on the ecosystem is not known in detail for the area and the results of the research carried out as part of the project might help the park managers and all the local authorities to define new strategies for more considerate land use.

\section{Initial results}

After three years of activity, the first major results are emerging and several data are currently being published in national and international scientific journals. In some cases, species new to science or for the Mercantour/Marittime area have been identified. Fabien and Laurent Soldati recently discovered a species never observed before in the Mercantour National Park, a Coleopteran of the genus Asida (Polasida). As of the end of 2009, a total of 4617 species have been reported from the Mercantour and Alpi Marittime parks, most of them (2787) insects. Within this class, Lepidoptera is the most represented order (1 872 species), followed by Coleoptera (481) and other orders with lower number of species identified (Figure 2). The plant kingdom is the second most numerous group with more than 900 recorded species, while 407 species are reported for fungi. Much still needs to be done in terms of improving the collecting strategies, data processing, communication among researchers and coordinators. Meanwhile, the amount of datasets compiled by the taxonomists (Figure 3) and the number of researchers in the field is growing (from 45 in 2007 to 112 in 2009), an indication that the project is raising interest in the scientific community.

After sampling and identifying the specimens, data from all researchers are gathered in the EDIT database and in another one available as part of the $\mathrm{Na}$ tional Inventory of Natural Heritage of the MNHN in Paris (http://inpn.mnhn. fr), which eventually becomes part of the Global Biodiversity Information Facility (http://www.gbif.fr/).

Some of the sampled specimens will be studied with all the modern systematics tools including DNA sequencing. Through the international project Barcode of Life, the genetic data provided by selected laboratories will be linked to the specimens sampled and hosted in the MNHN national collection and available on the Barcode of Life website (www. barcodinglife.org/).

Reference collections will be built and will include the species identified within the project. The National Museum of Natural History in Paris, France, and the Regional Museum of Natural Sciences in Turin (MRSN), Italy, already hold part of the known biodiversity of the Mercantour/Marittime territory in their collections and are able to put them together with the new specimens. Conserving specimens, especially holotypes (i.e. the specimens on which the formal description of the taxa is based), is extremely important for such a project. Collections can be examined by taxonomists, they provide an overview of the diversity of species that populate the Mercantour/Marittime territory to the wider public and they represent a point of reference for future projects and monitoring activities.

Local population

The ATBI project involves not only the scientific community but also the local population. The two parks include (sparsely) inhabited areas where humans engage in various activities throughout the year. In such a context, communi-

Researcherworking in the parkes. (C) Francesco Tomasinelli

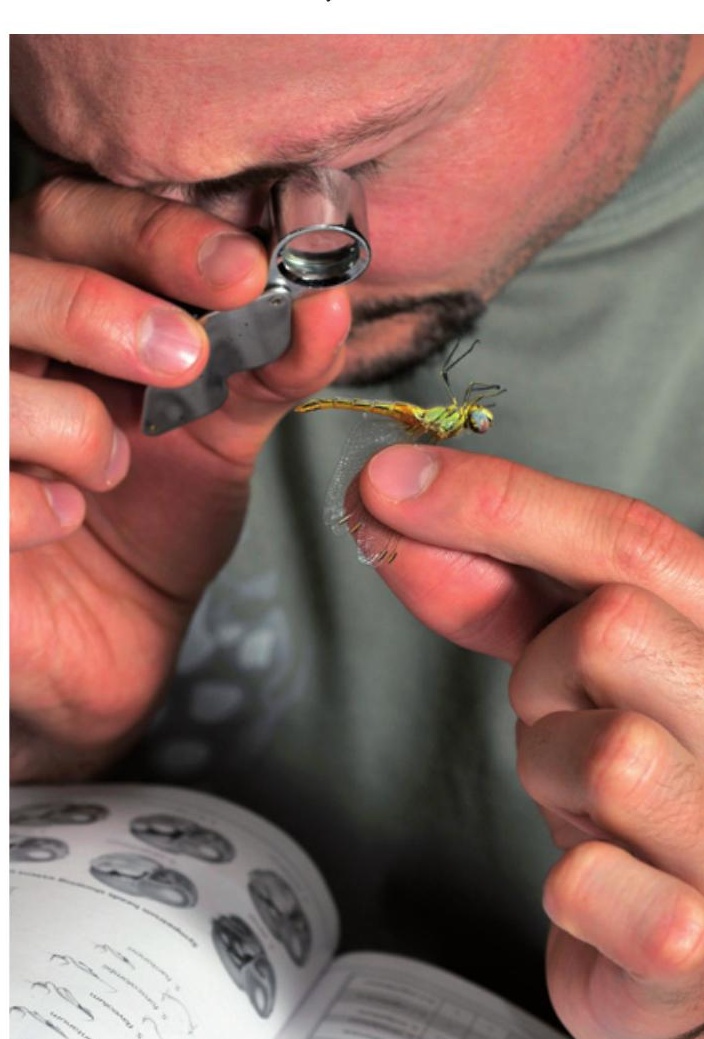


cation is an essential aspect of the project and needs to be conducted at many levels. Press releases and generic articles are published in newspapers or non-academic magazines and short communications are sent to the local authorities to inform them about imminent research activities. Moreover, a one-year course for the local primary schools was initiated with the aim of introducing budding scholars to the world of research, especially taxonomy.

The parks, but also the natural science museums, which play an important role in the dissemination of research findings, plan to prepare and host an exhibition informing the public and making it more aware of the significance of the ATBI project.

\section{Acknowledgment}

The project is funded by EDIT, the French Ministry of Environment, the Foundation Albert II of Monaco and the government of Monaco. Expenditures related to the ATBI+M are mainly for training and recruitment of field technicians (collecting, sorting, etc.), to cover the accommodation and travel costs for researchers, to provide research equipment and to perform scientific operations such as barcoding, preparing communication and didactic events.

We also have substantial support from the MNHN in Paris and the MRSN in Turin, which not only supply taxonomists but allow us to use the infrastructure needed to build a reference collection specific to our project and to perform the barcoding operations.

We would like to highlight the great effort made by each partner in the creation of an efficient network capable of bringing together high-quality expertise and involving it in large-scale research activities.

\section{Conclusion}

As outlined above, protected areas are in great need of information about the natural heritage they harbour. Conservation of natural resources is only possible if we know enough about biodiversity richness and conditions. The All Taxa Biodiversity Inventory is a new approach to help protected areas acquire in a short period of time a large amount of information which will be useful for the definition of land-use strategies that respect the ecosystem requirements and the legitimate needs of the local population.

\section{Authors}

Marta De Biaggi

Marta De Biaggi is a biologist specializing in ecology and wildlife conservation. She has been working for the Alpi Marittime Natural Park (Parco Naturale Regionale delle Alpi Marittime, Cuneo, Italy) as ATBI+M project coordinator since 2007 and collaborates with the park staff on freshwater fish management studies.

\section{Marie-France Leccia}

Marie-France Leccia is a biologist specializing in ecology and hydrobiology. She has been working for the Mercantour National Park (Parc National du Mercantour, Nice, France) as ATBI+M project coordinator since 2008. Previously, she worked for two years in a French research laboratory (LEHF, Univ. Lyon1/ CNRS) on hydrobiology and hydroecology.

\section{Alexander Kroupa}

(Dipl. Biol.) Alexander Kroupa is a scientist at the Museum für Naturkunde, Leibniz Institute for Research on Evolution and Biodiversity at the Humboldt University Berlin, Germany. His expertise is in the study of wasps and he works as IT expert for EDIT's Work Package 7.

\section{Juan Carlos Monje}

Dr. Carlos Monje is a scientist at the State Museum for Natural History, Stuttgart, Germany. His expertise is in the molecular taxonomy of minute parasitic wasps. He works as project coordinator and is one of the team leaders for EDIT's Work Package 7.
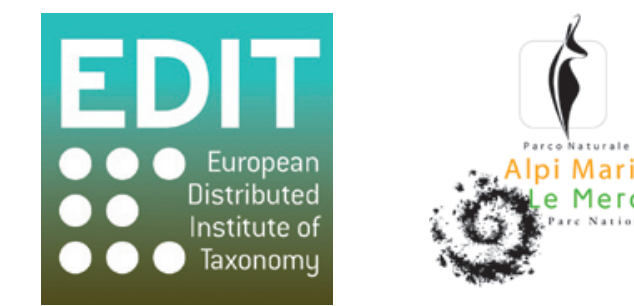

Al Marittime

e Mercantour

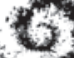

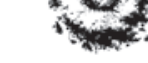

